\title{
Hope should not spring eternal
}

\author{
Jennifer S. Nelson, MD, MS
}

From the Department of Cardiovascular Services, Nemours Children's Hospital, Orlando, Fla; and Department of Surgery, University of Central Florida College of Medicine, Orlando, Fla.

Disclosures: Author has nothing to disclose with regard to commercial support.

Received for publication Oct 18, 2018; accepted for publication Oct 20, 2018; available ahead of print Nov 22, 2018.

Address for reprints: Jennifer S. Nelson, MD, MS, Department of Cardiovascular Services, Nemours Children's Hospital, 13535 Nemours Pkwy, Orlando, FL 32827 (E-mail: Jennifer.Nelson@ Nemours.org).

J Thorac Cardiovasc Surg 2019;157:1178-9

$0022-5223 / \$ 36.00$

Copyright (c) 2018 by The American Association for Thoracic Surgery

https://doi.org/10.1016/j.jtcvs.2018.10.086

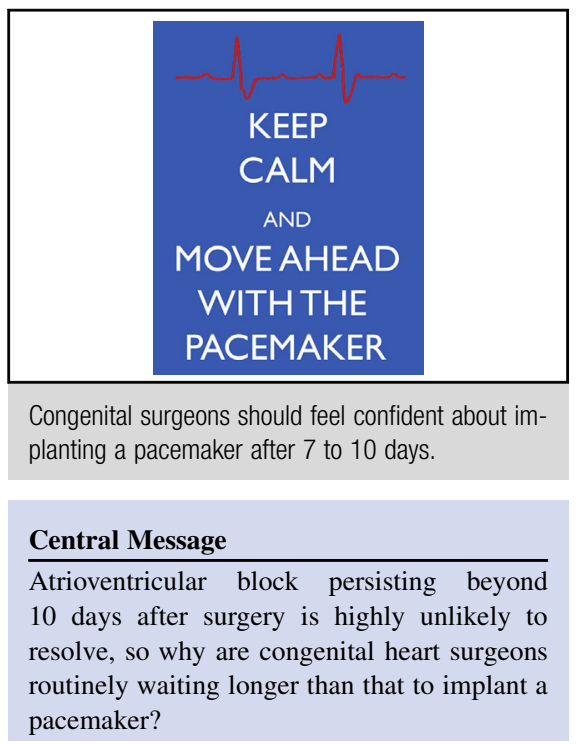

See Article page 1168
High-grade atrioventricular block (AVB) after congenital heart surgery is a dreaded complication affecting about $3 \%$ of patients. The study in this issue of the Journal by Romer and colleagues ${ }^{1}$ provides a contemporary description of the patients, operations, and timing related to AVB that is more granular than previous work. Romer and colleagues ${ }^{1}$ have used the Pediatric Cardiac Critical Care Consortium (PC4) registry to try to answer the million-dollar question that they pose: Who will need a PPM, and how long should we wait to implant it? In this analysis of more than 15,000 surgical hospitalizations from 25 congenital heart surgery referral centers, AVB occurred in $2.7 \%$ of cases, and in $1 \%$, a PPM was implanted.

Most of the time, AVB was evident in the operating room $(59 \%)$. Of those patients for whom this was true, $45.3 \%$ received a PPM, compared with $28.6 \%$ of patients who had AVB develop later in the intensive care unit. Not surprisingly, the highest PPM implantation rates were associated with patients with heterotaxy (2.2\% PPM rate) and patients undergoing high-risk operations (defined a priori by the authors) (2.1\% PPM rate) or Society of Thoracic Surgeons-European Association for CardioThoracic Surgery (STAT) category 4 or 5 operations (1.6\% PPM rate). Despite a laudable effort, Romer and colleagues $^{1}$ were unable to produce a reliable model for predicting the need for PPM during an index operation. They therefore do not recommend placement of wires or PPM in the operating room, even for the patients seemingly at highest risk.

The highlight of this study was the finding that for patients with transient AVB, 50\% had resolution by day 2, $86 \%$ by day 7 , and $94 \%$ by day 10 . Although it is not possible from the PC4 registry to know how many patients had resolution of AVB after discharge with a PPM, and conversely how many patients had late development of AVB, these results should make us feel confident about moving forward with a PPM by day 10 of postoperative AVB. As Romer and colleagues ${ }^{1}$ point out, however, only
$62 \%$ of PPMs in this study were placed by 10 days. Why are we delaying the inevitable?

The decision making surrounding PPM implantation is worthy of further investigation. Romer and colleagues observed significant variation across centers in the unadjusted incidence of AVB $(0 \%-6 \%)$ and the frequency of PPM placement ( $0 \%-3 \%)$. Current recommendations by the American College of Cardiology, the American Heart Association, and the Heart Rhythm Society include PPM implantation for advanced persistent AVB "that is not expected to resolve." 2 As surgeons, we typically do have expectations for either recovery or permanent complete heart block, assumptions that are based on the conduct of the operation. This study was not designed to measure individual surgeon factors, however, such as the ability to predict which patients will have permanent surgical AVB and the decision making that drives PPM wait time. Future collaborations should aim to understand these decisions and to reduce PPM practice pattern variation. PC4 is committed to collaborative quality improvement across centers, and the study of Romer and colleagues ${ }^{1}$ has identified an important initiative for the consortium to tackle next.

\section{References}

1. Romer AJ, Tabbutt S, Etheridge SP, Fischbach P, Ghanayem NS, Reddy VM, et al. Atrioventricular block following congenital heart surgery: analysis from the Pediatric Cardiac Critical Care Consortium. J Thorac Cardiovasc Surg. 2019;157:1168-77. 
2. Epstein AE, DiMarco JP, Ellenbogen KA, Estes NA III, Freedman RA, Gettes LS, et al; American College of Cardiology Foundation; American Heart Association Task Force on Practice Guidelines; Heart Rhythm Society. 2012 ACCF/AHA/ HRS focused update incorporated into the ACCF/AHA/HRS 2008 guidelines for device-based therapy of cardiac rhythm abnormalities: a report of the American College of Cardiology Foundation/American Heart Association Task Force on Practice Guidelines and the Heart Rhythm Society. J Am Coll Cardiol. 2013; 61:e6-75. 